Colloids and Surfaces A: Physicochem. Eng. Aspects 377 (2011) 54-62

doi:10.1016/j.colsurfa.2010.12.013

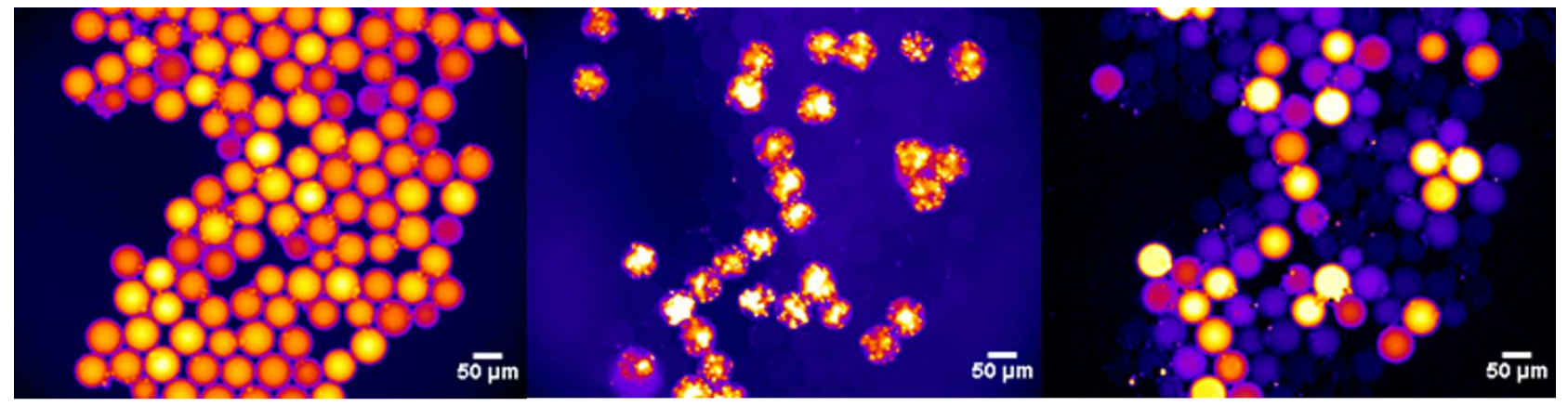

Single-cell characterisation and rapid enumeration of $E$. coli was achieved by confining them into the picoliter droplets of a water-in-oil fuorinated emulsion.

\title{
Micro-confinement of Bacteria into w/o Emulsion Droplets for Rapid Detection and Enumeration
}

Pierre R. Marcoux, ${ }^{* a}$ Mathieu Dupoy, ${ }^{\mathrm{a}}$ Raphael Mathey, ${ }^{\mathrm{b}}$ Armelle Novelli-Rousseau, ${ }^{\mathrm{b}}$ Virginie Heran, ${ }^{\mathrm{c}}$ Sophie Morales, ${ }^{\mathrm{a}}$ Florence Rivera, ${ }^{\mathrm{a}}$ Pierre L. Joly, ${ }^{\mathrm{a}}$ Jean-Pierre Moy ${ }^{\mathrm{a}}$ and Frédéric Mallard ${ }^{\mathrm{b}}$

* Corresponding author: Commissariat à l'Energie Atomique (CEA), LETI, MINATEC, 17 rue des Martyrs, 38054 Grenoble cedex 9, France. Fax: +334 387844 01; Tel: +334 387819 61; E-mail: pierre.marcoux @ cea.fr

${ }^{a}$ Commissariat à l'Energie Atomique (CEA), LETI, MINATEC, 17 rue des Martyrs, 38054 Grenoble cedex 9, France. Fax: +334 387844 01; Tel: +334 387819 61; E-mail: mathieu.dupoy@cea.fr; sophie.morales@cea.fr; florence.rivera@cea.fr; pierre.joly@cea.fr.

${ }^{\mathrm{b}}$ bioMérieux, bioMérieux - CEA joint team, 17 rue des Martyrs, 38054 Grenoble cedex 9, France. Fax: +334 387857 87; Tel: +334 387855 74; E-mail: raphael.mathey@cea.fr; armelle.novelli-rousseau@cea.fr; frederic.mallard@cea.fr

c Institut des Sciences Moléculaires de Marseille (iSm2), CNRS UMR 6263, Campus Scientifique de St Jérôme, 13397 Marseille cedex 20, France. Fax: +334 9128 91 87; Tel: +334 912888 42; E-mail: virginie.heran@univ-cezanne.fr

\section{Abstract}

Today, rapid detection and identification of bacteria in microbiological diagnosis is a major issue. Reference methods usually rely on growth of micro-organisms, with the drawback of lengthy time-to-result. The method provides global information on a clonal population that is known to be inhomogeneous relative to metabolic states and activities. Therefore, there may be a significant advantage of methods that allow characterization of individual bacteria from a large population, both for test time reduction and the clinical value of the characterization. We report here a method for rapid detection and real-time monitoring of the metabolic activities of single bacteria. Water-in-oil emulsions were used to encapsulate single Escherichia coli cells into picolitre $(\mathrm{pL})$-sized microreactor droplets. The glucuronidase activity in each droplet was monitored using the fluorogenic reporter molecule MUG (4-Methylumbelliferyl $\beta$-D-glucuronide) coupled to time-lapse fluorescence imaging of the droplets. Such bacterial confinement provides several major advantages. 
1) Enzymatic activities of a large number of single bacterium-containing droplet could be monitored simultaneously, allowing the full characterization of metabolic heterogeneity in a clonal population. We monitored glucuronidase enzymatic activity and growth over $\sim 200$ single bacteria over a $24 \mathrm{~h}$-period.

2) Micro-confinement of cells in small volumes allows rapid accumulation of the fluorescent metabolite, hence decreasing the detection time. Independent of the initial concentration of bacteria in the sample, detection of the presence of bacteria could be achieved in less than two hours.

3) Considering the random distribution of bacteria in droplets, this method allowed rapid and reliable enumeration of bacteria in the initial sample.

Overall, the results of this study showed that confinement of bacterial cells increased the effective concentration of fluorescent metabolites leading to rapid $(2 \mathrm{~h})$ detection of the fluorescent metabolites, thus significantly reducing time to numeration.

\section{Keywords}

w/o emulsion; bacteria encapsulation; bacteria enumeration; fluorosurfactant; single-cell characterisation; microdroplets

\section{Introduction}

There is a growing interest in encapsulation of cells into water-in-oil (w/o) emulsion as this way of compartmentalisation of an aqueous solution provides numerous microreactors, each allowing simultaneous biochemical reactions to be monitored. ${ }^{1,2,3,4}$ Every droplet is a pLscale microvessel and the continuous phase, the oil, is both a drop carrier and a barrier against cross-contamination between drops (referred to as In Vitro Compartmentalisation, IVC). That is why these w/o emulsions are considered a powerful tool to perform high-throughput screening. ${ }^{5}$ Aqueous microdroplets are also useful to conduct biological assays on single cells. During emulsification of a diluted suspension of cells, the majority of drops formed are empty with a low fraction of drops that are filled with one cell. This process is called stochastic confinement since the filling of a droplet during emulsification is random. $6,7,8,9$ This technique has allowed, for example, the study of the high-density communication behaviour ('quorum sensing') of a few bacteria, without influence from host factors. ${ }^{10}$ In another example, it has enabled the simultaneous determination of gene expression and enzymatic activity in single bacteria. ${ }^{11}$

Studies of stochastic confinement, may also lead to applications in the field of in-vitro diagnostic. For example, antibiotic susceptibility testing on single bacteria confined in nanolitre $(\mathrm{nL})$ droplets has been recently reported. ${ }^{12}$ Such an approach was faster compared with the conventional test for two reasons. First, by testing individual cells, an amplification step normally associated with conventional bacterial culture was not required before susceptibility testing. Secondly, micro-confinement allowed faster accumulation of fluorescent metabolites, hence reducing detection time and yielding a faster result about susceptibility.

Foodborne diseases continue to be significant causes of illness and death worldwide, it is therefore important to improve diagnostic tests for the detection and numeration of foodborne pathogens. Many of the tests are based on chromogenic or fluorogenic enzyme substrates. ${ }^{13}$ To date, attempts to reduce the assay time for the detection and enumeration have been impeded by the necessity to incubate the bacterial specimens for a few hours to days, in order to increase the cell density in samples to detectable levels. Single-cell analysis is expected to considerably decrease the time-to-result. The purpose of the present study was to monitor the enzymatic activity of single bacteria confined in micro-volumes using fluorescence microscopy over a 24 -h period. 


\section{Material and methods}

\subsection{Microfluidic device fabrication}

MFFD (Microfluidic Flow Focusing Devices) are made of polydimethylsiloxane (PDMS) using conventional soft lithographic techniques. ${ }^{14}$ Briefly, a master was prepared from Ordyl ${ }^{\circledR}$, a commercially available thick resist film $(50 \mu \mathrm{m})$, patterned with standard photolithography process on a silicon substrate. Silicone elastomer (sylgard 184, Dow Corning) was mixed in a 5:1 (w/w) ratio of resin to crosslinker and then poured over the master. After degassing, devices are cured for one hour at $65^{\circ} \mathrm{C}$. The cured PDMS is then peeled off the master. Access holes for fluidic tubing are created using a needle. Microfluidic chips are sealed with a PDMS cover using $\mathrm{O}_{2}$ plasma and are baked at $65{ }^{\circ} \mathrm{C}$ for 4 hours. Channels are made hydrophobic by silanisation so as to obtain the formation of aqueous droplets in a continuous oil phase.

\subsection{Synthesis of emulsifying agent}

The emulsifying agent DMP-PFPE (dimorpholinophosphinate perfluoropolyether) was prepared in a three step process: the synthesis of the hydrophilic head dimorpholinophosphate, the preparation of the fluorophilic tail perfluoropolyether and finally the coupling between the DMP head and the PFPE tail.

\subsubsection{Phenethyl dimorpholinophosphinate}

In a $500 \mathrm{~mL}$ three-necked flask under nitrogen, dry diethyl ether $(150 \mathrm{~mL})$ and $\mathrm{POCl}_{3}(7.8$ $\mathrm{mL}, 1.003 \mathrm{eq}$ ) were introduced successively at room temperature. The flask was cooled to $0^{\circ} \mathrm{C}$. Then a solution of phenethyl alcohol $(10 \mathrm{~mL}, 1 \mathrm{eq})$ and triethylamine $(29 \mathrm{~mL}, 2.5 \mathrm{eq})$ in dry diethyl ether $(110 \mathrm{~mL})$ was added dropwise at $0^{\circ} \mathrm{C}$ in $30^{\prime}$. Stirring was maintained for $1 \mathrm{~h}$. Then a solution of morpholine $(14.7 \mathrm{~mL}, 2 \mathrm{eq})$ and triethylamine $(60 \mathrm{~mL}, 5 \mathrm{eq})$ in dry diethyl ether $(110 \mathrm{~mL})$ was added dropwise at $0^{\circ} \mathrm{C}$ in $30^{\circ}$. The mixture was stirred overnight at room temperature. The solid was filtered off and washed with diethyl ether. The resulting filtrate was evaporated under vacuum, which yields $27.4 \mathrm{~g}$ of translucent oil. The crude oil was purified by column chromatography (silicagel, ethyl acetate/MeOH 9/1). After this purification step, we obtained $25.3 \mathrm{~g}$ of pure phosphinate as a translucent oil (yield=89\%).

- Thin-Layer Chromatography on silicagel, ethyl acetate:methanol 9:1 : Rf $=0.2$

- Nuclear Magnetic Resonance ${ }^{1} \mathrm{H}\left(300 \mathrm{MHz}, \mathrm{CDCl}_{3}\right): 3.04(10 \mathrm{H}, \mathrm{m}), 3.51(8 \mathrm{H}, \mathrm{m}), 4.16$ $(2 \mathrm{H}, \mathrm{m}), 7.26(5 \mathrm{H}, \mathrm{m}) \mathrm{ppm}$.

\subsubsection{PFPE acyl chloride}

In a $250 \mathrm{~mL}$ round bottom flask, Krytox 157 FSM (50 g, 1 eq) and perfluoromethyl cyclohexane $(50 \mathrm{~g})$ and dimethylformamide $(1 \mathrm{~mL})$ were added. The resulting mixture was refluxed and $\mathrm{SOCl}_{2}(1.5 \mathrm{~mL}, 1.65 \mathrm{eq})$ was added dropwise. The reaction mixture became white and then was refluxed overnight. The resulting biphasic mixture was decanted and the dark phase was removed. The white phase was evaporated under vacuum at $60{ }^{\circ} \mathrm{C}$, until no more distillate is obtained. The crude PFPE acyl chloride $(50 \mathrm{~g})$ was used without further purification in the next step.

\subsubsection{DMP-PFPE}

The phenethyl dimorpholinophosphinate that is obtained in step 1 (17 g, 4 eq) is mixed with the crude PFPE acyl chloride (50 g) and finely powdered aluminium chloride ( $2.5 \mathrm{~g}, 1.5 \mathrm{eq})$. The thick mixture was mechanically stirred and heated at $70{ }^{\circ} \mathrm{C}$ overnight. The semi-solid gum was cooled to room temperature and stirred with water $(1 \mathrm{~L})$. Then $\mathrm{NaOH} 1 \mathrm{~N}$ was added 
until $\mathrm{pH}$ became basic. The resulting mixture was stirred for $1 \mathrm{~h}$. The aqueous phase was removed and the gum was washed with water $(2 \times 1 \mathrm{~L})$ and methanol $(2 \times 1 \mathrm{~L})$. The resulting beige gum was dried under high vacuum for 4 days, so as to yield a semi-solid beige gum (40 g).

Nuclear Magnetic Resonance ${ }^{13} \mathrm{C}(400 \mathrm{MHz}, \mathrm{HRMAS}, \mathrm{s}=3 \mathrm{kHz})$ : 45.3(brs), 47.6(brs), 66.8(brs), 102.3(m), 104.9(m), 114.0(m), 117.0(m), 119.9(m), 122.7(d), 157.0(brs) ppm.

\subsection{Bacterial cell culture}

The Escherichia coli strain we used was E. coli BL21-Codon Plus-RIL Competent Cells (Stratagen, ref. 230240). Cells were transformed with the plasmid pDsRed Express (Becton Dickinson, ref. 632412). This plasmid codes for DsRed fluorescent protein (excitation: 557 $\mathrm{nm}$; emission: $579 \mathrm{~nm}$ ) and provides ampicillin resistance through $\beta$-lactamase expression.

After a preculture phase overnight $\left(17 \mathrm{~h}\right.$ at $30^{\circ} \mathrm{C}$ without stirring) in Lysogenic Broth (LB medium Lennox, Q-Biogene) with ampicillin (100 $\mathrm{mg} / \mathrm{L})$, cell concentration was adjusted to $\mathrm{OD}_{550}=0.7$ (Optical Density at $550 \mathrm{~nm}$ ). Then $4 \mathrm{~mL}$ of LB medium supplemented with $100 \mathrm{mg} / \mathrm{L}$ ampicillin was inoculated at $1 / 50$ dilution with precultured bacteria $(80 \mu \mathrm{L}$ of preculture medium) prior to incubation at $37^{\circ} \mathrm{C}$ with stirring at $250 \mathrm{rpm}$. After this step, the measured $\mathrm{OD}_{550}$ of the culture was 0.278 , corresponding to $5.6 \times 10^{7} \mathrm{cfu} / \mathrm{mL}\left(2.10^{7} \mathrm{cfu} / \mathrm{mL}\right.$ for $0.1 \mathrm{OD}_{550}$ was demonstrated using the growth medium used in the study, data not shown). Bacteria from this culture were then diluted in fluorogenic culture medium (dilution factor of $1 / 556$ ), so as to obtain a theoretical $10^{5} \mathrm{cfu} / \mathrm{mL}$ suspension in the fluorogenic medium. The time of this dilution (and medium transfer) was set as $t=0$ time of the enzymatic assay in all experiments. As a control, part of this suspension was also immediately spread on chromID CPS3 (bioMérieux) and LB agar plates (LB agar Lennox, Q-Biogene), in order to measure the bacterial concentration at $t=0$ according to the standard enumeration method.

Rapid methods for the detection of $E$. coli and coliforms are based on the assumption that $\beta$-D-glucuronidase and $\beta$-D-galactosidase are markers for $E$. coli and coliforms respectively. ${ }^{15}$ Our fluorogenic culture medium contains substrate for $\beta$-D-glucuronidase (Fig. 1a) and was optimised so as to increase the glucuronidase activity. It also contains a pH stabilisation buffer, so as not to alterate the fluorescence of fluorescein and 4-MU that are $\mathrm{pH}-$ dependant. The composition of this medium is MOPS (4-Morpholinepropanesulfonic acid sodium salt) $150 \mathrm{mM}$; magnesium sulfate $2,6 \mathrm{mM}$; sodium glucuronate $854 \mu \mathrm{M}$; methyl $\beta$-Dglucuronide $870 \mu \mathrm{M}$; MUG (4-methylumbelliferyl- $\beta$-D-glucuronide) $113 \mu \mathrm{M}$; fluorescein $4.15 \mu \mathrm{M}$; ampicillin $100 \mathrm{mg} / \mathrm{L}$. The $\mathrm{pH}$ buffer is 7.33 .

\subsection{Bacteria encapsulation and enzymatic assay}

Aqueous droplets are formed using a Microfluidic Flow Focusing Device (MFFD). ${ }^{16,17}$ The geometry is that of a conventional MFFD, except the triangular chamber downstream of the nozzle (Fig. 1b). This triangular enlargement has been proposed by Tan et al. ${ }^{18}$ to focus the velocity gradient at the nozzle.

The movement of oil and aqueous solution is controlled using a pressure-based flow control system (Fluigent ${ }^{\circledR}$ MFCS-8C-1000 mbar). All the pressures reported are relative to atmosphere. The oil phase is a solution of DMP-PFPE fluorosurfactant at $5 \% \mathrm{w} / \mathrm{w}$ in perfluorotripentylamine (Fluorinert FC-70, 3M Corp.). The aqueous phase is the $10^{5} \mathrm{cfu} / \mathrm{mL}$ of $E$. coli in the fluorogenic medium. Relative pressures are adjusted to get a droplet formation frequency of dozens of drops per second.

The formed droplets have a mean diameter of $73 \mu \mathrm{m}(\sigma=7 \mu \mathrm{m})$ and a mean volume of $210 \mathrm{pL}(\sigma=70 \mathrm{pL})$. They are stored as a monolayer in a buffer tank covered with a $73 \times 26 \mathrm{~mm}$ microscope glass slide $(0.17 \mathrm{~mm}$ thick). When the buffer tank is filled with droplets, driving pressure is immediately stopped, to stop emulsification process. It takes $1 \mathrm{~h} 45$ minutes to fill 
the tank. If bacteria are diluted enough in the aqueous phase to be divided, we can neglect the fluorescence increase that may occur for some drops between $t=0$ and the moment of the encapsulation in the MFFD. After filling the buffer tank, the monitoring of fluorescence starts on 56 microscope fields chosen in the areas presenting a high density of droplets (as shown in Fig. 1c). Every selected field is observed every hour, from $t=2 \mathrm{~h}$ to $t=22 \mathrm{~h}$, in order to measure the fluorescence intensities of fluorescein, DsRed protein and 4-MU. These observations are made with an Axio Imager microscope (Zeiss) using a 10× objective $(0.17$ mm cover glass correction, NA 0.5).

Since the cell density $c$ of the aqueous phase at $t=0$ is $10^{5} \mathrm{cfu} / \mathrm{mL}$, namely $c=0.1$ $\mathrm{cfu} / \mathrm{nL}$, we can consider that all the filled droplets contain no more than a single bacterium. Indeed, a majority of droplets have a volume $V=200 \mathrm{pL}$. Therefore we obtain a mean occupancy $c V$ of 0.02 , and we infer from Poissonian statistics $p(x)=(c V)^{x} e^{-c V} / x$ ! that the single, double and triple occupancies are $p(1)=0.2 \%, p(2)=2.10^{-4} \%$ and $p(3)=2.10^{-7} \%$, respectively. Single occupancy at $t=0$ simplifies the interpretation but is not a limitation of the enumeration method.

\section{Results and discussion}

\subsection{Emulsion formulation}

The emulsion formulation is of critical importance to provide efficient IVC. The choice of the oil phase and emulsifying agent was determined by the following considerations.

Continuous phase has to fulfil a number of requirements. It has to be an efficient impediment to diffusion between droplets. Its viscosity must be high enough to enable the formation of droplets through shear stress, but not too excessive to avoid huge pressure drops in fluidic systems. ${ }^{19}$ Continuous phase has to allow for the exchange of gases, especially when an aerobic strain is encapsulated. So an oil with good solubility for gases is preferred. Finally, oil has to be biocompatible and therefore it must be a poor solvent: molecules that would dissolve some components of the bacterial membrane are not adapted (such as toluene ${ }^{20}$ for example).

Continuous phase can be chosen among the most common groups of oils: fatty acid esters (isopropyle palmitate, cetearyl isononanoate, etc.), mineral oils (paraffinic oils, naphthenic oils, etc.), heavy alcohols and long fatty acids (decanol, oleic acid, etc.), vegetable oils (soybean oil, castor oil, etc.), silicone oils (hexadimethylsiloxane, dimethicon, etc.) and fluorinated oils (perfluorodecalin, perfluorotributylamine FC-43, etc.). In particular, silicone and fluorinated oils are particular since they are simultaneously hydrophobic and lipophobic. They are consequently the most adapted continuous phases for IVC experiments. Furthermore, they both show good solubilities for gases. For example, oxygen is at least ten times as soluble in silicone oil (polydimethylsiloxan at 1 centistoke) as in plasma or saline. Previous studies have reported that goldfish had survived under such an oil for several weeks. ${ }^{21}$ The solubility of gases is even higher in perfluorinated liquids, such as FX-80 (perfluoro-2butyltetrahydrofuran) and perflubron (perfluorooctyl bromide), and, thus, have been studied since the sixties for partial liquid ventilation (administrated to premature infants for example), 22 or as blood substitutes. ${ }^{23,24}$ The solubility of oxygen in this kind of liquids is typically 35 $44 \mathrm{mmol} / \mathrm{L}\left(2.2 \mathrm{mmol} / \mathrm{L}\right.$ in water), and more than $200 \mathrm{mmol} / \mathrm{L}$ for carbon dioxide. ${ }^{25} \mathrm{In}$ literature, perfluorinated liquids are more frequently used in IVC than silicone oils. Indeed, fluorinated oils are more efficient than silicone oils to prevent cross-contamination between droplets. Nevertheless, the suspected toxicity and the strong remanence of perfluorinated compounds ${ }^{26}$ require circumspection today regarding the common use of perfluorinated oils. A recent paper by Courtois et al. ${ }^{27}$ proposed an interesting alternative to fluorinated continuous phases in the field of IVC: the addition of amphiphilic protein BSA (bovine serum 
albumin) substantially reduced leaking of the fluorophore into the oil phase (mineral oil). In our study, we focused our formulation trials on silicone oil AR-20 (polyphenylmethylsiloxane, $20 \mathrm{mPa} . \mathrm{s}$ ) and on fluorinated oil FC-70 (perfluorotripentylamine, $27 \mathrm{mPa} . \mathrm{s}$ ).

Since we want to stabilise a w/o emulsion, the emulsifying agent has to be an amphiphilic molecule that shows more affinity with continuous phase than with dispersed phase (Bancroft's rule). In terms of hydrophilic-lipophilic balance (HLB), we need low HLB surfactants. ${ }^{28}$ Ideally, this surfactant should be soluble in the oil phase, but not in water. Secondly, in order to impede the coalescence of adjacent droplets, it is better to use surfactants showing slow exchange kinetics between interfacial zone and the two phases (continuous and dispersed). That is why amphiphilic polymers are often used as emulsifying agents. A silicone oil necessitates a silicophilic/hydrophilic polymer, such as Abil EM-90 (Cetyl PEG/PPG-10/1 Dimethicone), ${ }^{29,30}$ whereas a fluorinated continuous phase requires a fluorophilic/hydrophilic molecule, such as a PFPE-PEG block copolymer (perfluoropolyetherpolyethylene glycol). ${ }^{31}$ Regarding biocompatibility, a non-hydrosoluble emulsifying agent is also most suitable to prevent contact of the cells with surfactants. Moreover, the charged headgroups of surfactants may interact with charged biomolecules and result in their denaturation. ${ }^{32}$ For example, the cationic surfactant CTAB (cetyltrimethylammonium bromide) has a lethal effect, not only on bacterial species, such as Bacillus subtilis and Pseudomonas aeruginosa, ${ }^{33}$ but also on eukaryotic cells, such as Saccharomyces cerevisiae. ${ }^{34}$ The antibacterial effect of an anionic surfactant like SDS (sodium dodecyl sulfate) has also been reported. ${ }^{35}$ On the contrary, the toxicity of neutral surfactants is considerably lower. ${ }^{36}$ As a conclusion, bacterial encapsulation into w/o emulsions requires emulsifying agents with non-ionic hydrophilic headgroups. Regarding silicone oils, many surfactants that fulfil this requirement are commercially available, such as Abil EM-90 (Sunjin Chemical Co.), DC5225C (Dow Corning) or KF-6017 (Sunjin Chemical Co.). In contrast, the choice of commercially available fluorosurfactants that stabilise water-in-oil emulsions is strongly limited. Indeed, most of fluorosurfactants have been designed to stabilise direct emulsions and are thus too much hydrophilic, such as Zonyl molecules (DuPont). Recent publications have reported the synthesis and the use of new fluorosurfactants in droplet compartmentalisation, 31,37,38,39 like DMP-PFPE, PEG-PFPE or poly-L-lysine-PFPE (DMP: dimorpholinophosphate, PEG: polyethylene glycol, PFPE: perfluoropolyether).

We finally chose to try two formulations: a silicone one, Abil EM-90 (emulsifying agent) dissolved in polyphenyl-methylsiloxane AR-20 (oil), and a fluorinated one, DMPPFPE (emulsifying agent) dissolved in Fluorinert FC-70 (perfluorotripentylamine, oil). As a first step, we prepared a w/o emulsion (10\%v/v water) with a solution of Abil EM-90 in AR20 silicone oil at $0.1 \% \mathrm{w} / \mathrm{w}$ as a continuous phase. The dispersed phase was an aqueous suspension of $E$. coli in our fluorogenic buffer at $3.6 \times 10^{7} \mathrm{cfu} / \mathrm{mL}$. This formulation was not toxic for bacteria since we observed cell divisions in the first $24 \mathrm{~h}$ (data not shown). However, it did not fulfil the IVC requirements since it does not prevent diffusion between droplets. This solute transfer is called compositional ripening and originates in the fact that the equilibrium state is an emulsion in which every droplet has the same chemical composition. ${ }^{40,41}$ As a consequence, this ripening starts as soon as bacteria degrade MUG enzymatic substrate: 4-MU fluorophore diffuses from the drops containing cells to the empty droplets. Alternatively, a flow of MUG takes place from the empty droplets to the filled ones. In the case of silicone formulation, we observed a massive transfer of 4-MU fluorophore in less than 3 hours after emulsification, so that the 4-MU concentration was the same throughout the whole dispersed phase (data not shown).

The solute transfer through the continuous phase is reported as a molecular transport in which the surfactant micelles present in the oil act as carriers for droplet solutes. ${ }^{40,42}$ Owing to this "micelle carrier mechanism", a way of hindering compositional ripening is to 
use emulsifying agents with a high CMC (critical micellar concentration) and to use a surfactant concentration as low as possible. Alternate solutions include the addition of an amphiphilic macromolecule (such as BSA), ${ }^{27}$ that adsorb at the drop interface or the use of a fluorinated oil. We chose to encapsulate bacteria into fluorinated w/o emulsions, as reported by Clausell-Tormos et al., ${ }^{37}$ with a solution of DMP-PFPE in FC-70 at $5 \% \mathrm{w} / \mathrm{w}$ as a continuous phase.

Another type of mass transfer is also usually observed: Ostwald ripening, which is the diffusion of the dispersed phase material, water in our case, from smaller droplets to larger ones. This water transportation is caused by the difference in curvature radius of the dispersed phase droplets, and consequently, the difference in chemical potential of substances within the droplets. ${ }^{43}$ As a result, small droplets become smaller and large droplets become larger, leading to droplet size growth and interfacial area reduction. Ostwald ripening rate depends on the average radius of droplets and ripening slows down when drops get larger. That is why, as the Lifshitz-Slezov-Wagner (LSW) model shows, this phenomenon is much slower for micrometric drops. ${ }^{44}$ According to LSW equation, for micrometer-sized drops, the diameter increase is not measurable over a few hours time scale. In our experiments, we compared the size distributions of droplets between the beginning and the end of incubation, and no Oswald ripening was observed.

\subsection{Monitoring of enzymatic activity}

Three fluorescence intensities were measured in this study, as shown in Fig. 2: fluorescein, DsRed and 4-MU. The first two intensities are reference signals that could be suppressed in an enzymatic assay. All three of them are monitored from $t=2 \mathrm{~h}$ to $t=22 \mathrm{~h}$ (Fig. 3 and Fig. 4).

Fluorescein is the reference fluorophore. Indeed, its concentration is constant versus time since it is not produced in situ like 4-MU. Furthermore, its concentration is the same in every droplet and therefore it is not subject to compositional ripening. Fig. 4a plots the fluorescence intensity of fluorescein as a function of time, between $t=2 \mathrm{~h}$ and $t=22 \mathrm{~h}$, for the six droplets delineated in Fig. 2d. Fluorescein is not required if droplets are monodisperse: it becomes essential to normalise fluorescence signals when diameter distribution gets wider. Finally, fluorescein can be used as a fluorescent probe for $\mathrm{pH}$ measurements, since its fluorescence depends on $\mathrm{pH}\left(\mathrm{pK}_{\mathrm{A}} 2.2 ; 4.4 ; 6.4\right) .{ }^{45}$ Therefore, our results from Fig. 4a show that $\mathrm{pH}$ is stable within droplets during incubation, thanks to MOPS buffer $(150 \mathrm{mM})$. Such a conclusion is important since 4-MU fluorescence also depends on $\mathrm{pH}$.

The DsRed protein enables a straightforward distinction between full droplets, i.e. those that include at least one bacterium at $t=0$, and empty droplets, namely without bacterial cells (see Fig. 2b). In the same way as mRFP labelling protein, ${ }^{46}$ the fluorescence of DsRed is confined in the cells since it does not cross bacterial membrane. ${ }^{47}$ DsRed also reveals the division of bacteria after encapsulation into drops. As seen in Fig. 2b, confined E. coli have already divided at $t=8 \mathrm{~h}$. We have noticed that one to two divisions happened before $t=4 \mathrm{~h}$ in the majority of full droplets. This observation is in accordance with the generation time we measured in our fluorogenic nutrition medium (approximately 2 hours, data not shown) and reveals the biocompatibility of the chosen formulation. In order to quantify the growth inside drops, the fluorescence intensity of DsRed protein was normalised against fluorescein. Based on this normalisation, we can take into account the volume differences between droplets, as well as the slight illumination heterogeneities. As illustrated in Fig. 4b, DsRed fluorescence allows an easy distinction between empty and filled droplets: the empty droplet, number 6, presents a low and constant normalised fluorescence, whereas the other five drops, which are full, exhibit an increase and then variations of fluorescence due to field depth. E. coli cells tend to move inside droplets, hence focus might be lost at times, causing the measured DsRed fluorescence to decrease. That is why we decided to consider the maximum of the normalised 
DsRed fluorescence in order to make the distinction between full and empty droplets. This sorting yielded 214 full droplets among the 3902 droplets we studied in the 56 selected microscope fields.

The 4-MU is produced inside bacterial cells through the glucuronidase activity and is then released within the droplets since it permeates through bacterial membranes. As a consequence, a droplet filled with a bacterium shows higher 4-MU fluorescence intensity than its adjacent empty drops. The phenomenon of compositional ripening causes a mass transfer of the 4-MU aqueous solute from a filled droplet to the adjacent empty ones, as illustrated in Fig. 3. It is worth noting the low probability of finding two adjacent filled droplets $(0.3 \%)$, since the occupancy rate is rather low. Therefore, the 4-MU fluorescence we can measure around a filled drop cannot be due to the occupancy of several adjacent drops. These observations lead to the conclusion that the DMP-PFPE emulsifying agent considerably slows down the kinetics of compositional ripening, but it does not suppress it totally.

Like DsRed, we also normalised the 4-MU fluorescence against the reference fluorescein, as shown in Fig. 4c, which plots the normalised intensity of 4-MU in the six droplets delineated in Fig. 2d. The presence of "fluorescence bursts", defined by sudden increases of temporal derivative, in some of the curves of Fig. 4c, is remarkable (see vertical arrows). Interestingly, these curves illustrate several events:

- a full droplet with a high glucuronidase activity (drop 1), with progressive decay and no burst;

- $\quad$ some full drops with several bursts (droplets 3 and 5);

- a non detected full drop, for it does not show any measurable enzyme activity (droplet

4);

- $\quad$ an empty drop, indicated as a reference (droplet 6);

- a full drop showing a low glucuronidase activity (droplet 2), that we can detect if the detection threshold concerns the derivative of fluorescence intensity (as seen in the inset, there is a burst at $t=2 \mathrm{~h}$ ).

We can infer from Fig. 3 that this fluorescence burst at $t=2 \mathrm{~h}$ in drop 2 cannot be attributed to compositional ripening, but to a true increase of glucuronidase activity. Such a sudden gain of enzymatic activity might be due to a daughter cell that starts its own metabolism. This assumption cannot be proved since we do not possess an accurate measurement of cell divisions within droplets. Besides, there is often a lag between bacterial division and metabolic activity. It may also be due to the enzyme induction of $\beta$-D-glucuronidase ${ }^{15}$ in one of the encapsulated cells.

In order to specify a relevant detection threshold for the derivative of 4-MU fluorescence, we plotted the maximum of the absolute value of this derivative as a function of the maximum of DsRed fluorescence (Fig. 5a). In this way, we depict the maximum of apparent enzymatic activity as a function of bacterial growth. We decided to consider the absolute value of the derivative, and not the derivative itself, since we observed that some droplets reached their maximum enzymatic activity before $t=2 \mathrm{~h}$. In Fig. 5a, the empty droplets cluster in the lower left corner of the plot. In the lower right part of the plot, we can see the full droplets with bacterial growth, but without measurable enzymatic activity. By setting the detection threshold at $0.2 \mathrm{~h}^{-1}$ (dashed line in Fig. 5a), we are able to differentiate full droplets from empty ones since no empty drop reach that level. Using that threshold, we can plot the fraction of detected encapsulated bacteria as a function of time (Fig. 5b). More than half of the confined bacteria are detected in four hours and a plateau at $74 \%$ is reached after ten hours of incubation. As a conclusion, a quarter of the encapsulated bacteria at $t=0$ do not exhibit a detectable enzymatic activity, even after 22 hours of incubation at $37^{\circ} \mathrm{C}$. Such a result might be explained by the fact that the MUG substrate is not the only carbon source in nutrition medium. 


\subsection{Enumeration methods and controls}

Stochastic confinement does not only yield a single-cell characterisation (we measured the heterogeneity of bacterial population), it also allows enumeration. Concerning enumeration, we have two types of controls: 1) pre-poured growth medium Petri dishes are inoculated at $t=0$ with the aqueous phase before emulsification, and 2) the DsRed labelling allows a control of the effective presence of bacteria in droplets, independent on their metabolic activity.

We estimated bacteria number using two methods based on DsRed labelling:

1. We simply made the ratio between the 214 droplets exhibiting DsRed fluorescence and the explored volume, that is to say the total volume of the 3902 studied droplets $(0.811$ $\mu \mathrm{L})$. It yields an estimate of the concentration as $2.6 \times 10^{5} \mathrm{cfu} / \mathrm{mL}$.

2. The second estimation was based on Poisson's law and on the assumption that all the droplets have the same volume $V=208 \mathrm{pL}$ (the average volume). Since the measured occupancy rate is $5.48 \%$ and $p(n \geq 1)=1-p(0)=1-e^{-c V}$, we conclude $1-e^{-c V}=5.48 \times 10^{-2}$. We infer from this equation the value of the product $c V, c V=0.058$, and that the concentration $c$ equals $2.8 \times 10^{5} \mathrm{cfu} / \mathrm{mL}$.

The second type of control is the standard enumeration method, based on agar plates. We inoculated both chromID CPS3 agar plates (chromogenic medium for the enumeration and identification of Escherichia coli) and LB agar plates (non selective growth medium). CPS3 plates and LB plates yielded $1.7 \times 10^{5} \mathrm{cfu} / \mathrm{mL}$ and $2.0 \times 10^{5} \mathrm{cfu} / \mathrm{mL}$ values, respectively.

Similarly, our enumeration method based on enzymatic activity can also be performed in two ways, using the total volume of the studied droplets, or the Poissonian statistics. If we determine the ratio between the 158 bacteria detected after 22 hours according to the 4-MU fluorescence (the plateau on Fig. 5b), and the explored volume, we finally deduce $c=2.0 \times 10^{5}$ $\mathrm{cfu} / \mathrm{mL}$. These 158 detected cells reveal an occupancy rate of $4.05 \%$. Poisson's law yields $p(n \geq 1)=1-e^{-c V}=4.05 \times 10^{-2}$, so $c=2.0 \times 10^{5} \mathrm{cfu} / \mathrm{mL}$. It is important to notice that a proper enumeration can be done after only ten hours of incubation (Fig. 5b): if we take into account the number of bacteria detected at $t=10 \mathrm{~h}$, that is to say 155 , the enumeration results are almost the same. As a conclusion, our enumeration method is in good agreement with the standard agar plate method. In contrast, the enumeration result is lower than that obtained with the DsRed labelling. This slight discrepancy is consistent with the lack of glucuronidase activity that we observed for $1 / 4$ of the encapsulated cells.

\section{Conclusions}

The aims of the present study were to determine the value of in-vitro compartmentalisation technique as a means to provide detection and enumeration of bacteria much faster than conventional methods based on bacterial growth in agar media. We showed that some bacteria could be detected very early (less than 2 hours) and that enumeration could be performed in less than 10 hours. Our technique is based on stochastic confinement of cells in pL-sized droplets of the sample to be analysed. Metabolic activity of single bacterial cells is then monitored using the fluorochrome-coupled metabolic tracer molecule MUG. Rapid accumulation of the fluorescent degradation product 4-MU in droplets harbouring betaglucuronidase-positive bacterial cells allow fast and accurate estimation of the occupancy rate and initial concentration of these bacteria in the sample.

Micro-confinement of bacteria into picoliter droplets has two benefits. First, fast accumulation of fluorescent tracer in occupied droplets due to micro-confinement of bacteria allows detection of the most active bacteria in less than $2 \mathrm{~h}$, while methods based on culture of the whole sample and bacterial growth would take much longer. Second, digital counting enables us to estimate more rapidly the total concentration of bacteria in the initial sample using stochastic repartition laws than the conventional agar plating technique. 
By using a DsRed-labelled strain, our single-cell analysis outlined the heterogeneity of bacterial population and showed that $1 / 4$ of the studied bacteria are viable (since they divide), but do not yield detectable enzymatic activity. Nevertheless, our enumeration results, based on enzymatic activity, are in good agreement with conventional agar plate methods based on colony count.

Our actual efforts focus now on evaluating the dynamic range of such an alternative enumeration system. The major issue of compositional ripening remains unresolved and restricts the dynamic range by preventing storage of two filled droplets side by side. Emulsion formulation still requires further optimisation. In spite of this, emulsification provides a simple means to confine single cells in very small volumes where their metabolic activity can be monitored individually. A large number of droplets can be stored in a small volume compared with other existing confinement methods based on nebulisation and volume separation in micro-cuvettes. Such advantages open the way towards rapid and compact diagnostic systems for detection and enumeration of bacteria in contaminated sample.

In comparison, flow cytometry is also a rapid flow of single cells in file through a channel: it is faster than our method (up to 30000 cells/s for a FACS system), and with a wider dynamic range (up to $\sim 10^{8}$ analysed cells). ${ }^{48}$ However, the use of flow cytometry is not yet adapted to the single-cell study of metabolic processes. The technology is restricted to dyes that remain inside cells, and is not compatible with a kinetic study since it allows for a unique optical measurement. In contrast, our methodology has a significant potential for investigating a wide range of metabolic processes of individual bacteria or eukaryotic cells. By analysing the metabolites of single-cells as a function of time, it provides an insight into intrapopulation variability of cells and gives a quantitative analysis of population heterogeneity.

\section{Acknowledgement}

The authors want to express their gratitude to Pradip Patel, bioMérieux, for his constructive review of this manuscript.

\section{Captions}

\section{Fig. 1}

Bacterial cell encapsulation and enzymatic assay (a) Degradation of glucuronidase substrate MUG (4-Methylumbelliferyl- $\beta$-D-glucuronide) into fluorescent 4-MU (4Methylumbelliferone). (b) Schematic of a MFFD. At the nozzle, the continuous phase hydrodynamically focuses the dispersed phase into a narrow channel that connects to a large opening: the stretching and pinching of the dispersed aqueous thread result in the formation of droplets. Every aqueous droplet is either empty or includes a single bacterium, provided that the concentration of bacteria in aqueous phase is low enough. (c) Monodisperse aqueous droplets can stack together into a 2D-hexagonal lattice. The maximum surface compacity of such an array is $91 \%(\pi / 2 \sqrt{ } 3)$, which means $\sim 300$ droplets $/ \mathrm{mm}^{2}$.

\section{Fig. 2}

Example of a given field imaged at $t=8 \mathrm{~h}$. (a) The fluorescence of the reference fluorophore (fluorescein) provides with a localisation of all the droplets. (b) The fluorescence of DsRed protein yields a localisation of bacteria. DsRed protein does not cross cell membranes, that is why this fluorescence is confined in bacteria cells. At $t=8 \mathrm{~h}$, bacteria have already divided. (c) The fluorescence of 4-MU is originated from $\beta$-glucuronidase activity. 4-MU molecules diffuse from full droplets to empty ones because of compositional ripening. (d) Merging 
images $a$ (fluorescein) and $b$ (DsRed) outlines full droplets. Here are shown the six droplets (five full ones and an empty one) that will be studied further in details as an example.

\section{Fig. 3}

Fluorescence of 4-MU between $t=2 \mathrm{~h}$ and $t=17 \mathrm{~h}$, for the zone represented on Figure 2 (scalebar : $50 \mu \mathrm{m}$ ). Droplet 6 is empty. The five other drops are full. Compositional ripening originates in the full droplets 1, 5 and 3: the fluorophore 4-MU diffuses from the droplets where it is produced to the adjacent droplets without bacteria.

\section{Fig. 4}

The fluorescence intensity of the different fluorophores as a function of incubation time for the six droplets outlined in Figure 2d. The droplets 1 to 5 are full, the 6 is empty. $t=0$ is the moment of the encapsulation of cells into microdroplets. Legend is identical in the three plots $a, b$, and $c$. (a) The fluorescence of the reference fluorophore (fluorescein) is constant since this fluorophore is not produced by bacteria. (b) The normalised fluorescence of DsRed protein is shown (normalised against the fluorescence of fluorescein). It generally increases since bacteria divide after encapsulation. Strong variations may then be observed due to depth field: since bacteria move inside droplets, they sometimes go out of focus, causing a decrease of collected fluorescence. (c) The normalised fluorescence of 4-MU is plotted. The arrows indicate a fluorescence burst, due to a sudden increase of enzyme activity. The inset in the top right corner is an enlargement of the graph in the first eight hours.

\section{Fig. 5}

Bacteria detection through 4-MU fluorescence measurements. (a) The maximum of the absolute value of the temporal derivative of normalised 4-MU fluorescence ( $\mathrm{I}_{4 \mathrm{MU}}$, expressed in arbitrary units. $\mathrm{h}^{-1}$ ) is plotted against the maximum of normalised DsRed fluorescence ( $\mathrm{I}_{\text {DsRed }}$, expressed in arbitrary units), for 184 full droplets and 128 empty droplets. Fluorescence intensities are normalised versus fluorescein. A threshold of $0.2 \mathrm{~h}^{-1}$ is chosen, so as to discriminate detected encapsulated bacteria from non-detected bacteria. (b) Fraction (\%), among full droplets, of detected bacteria versus time. Detection is based on the $0.2 \mathrm{~h}^{-1}$ threshold (dashed line on Figure 5a) on the derivative of 4-MU signal. A plateau is reached after 10 hours of incubation at $37^{\circ} \mathrm{C}$. 

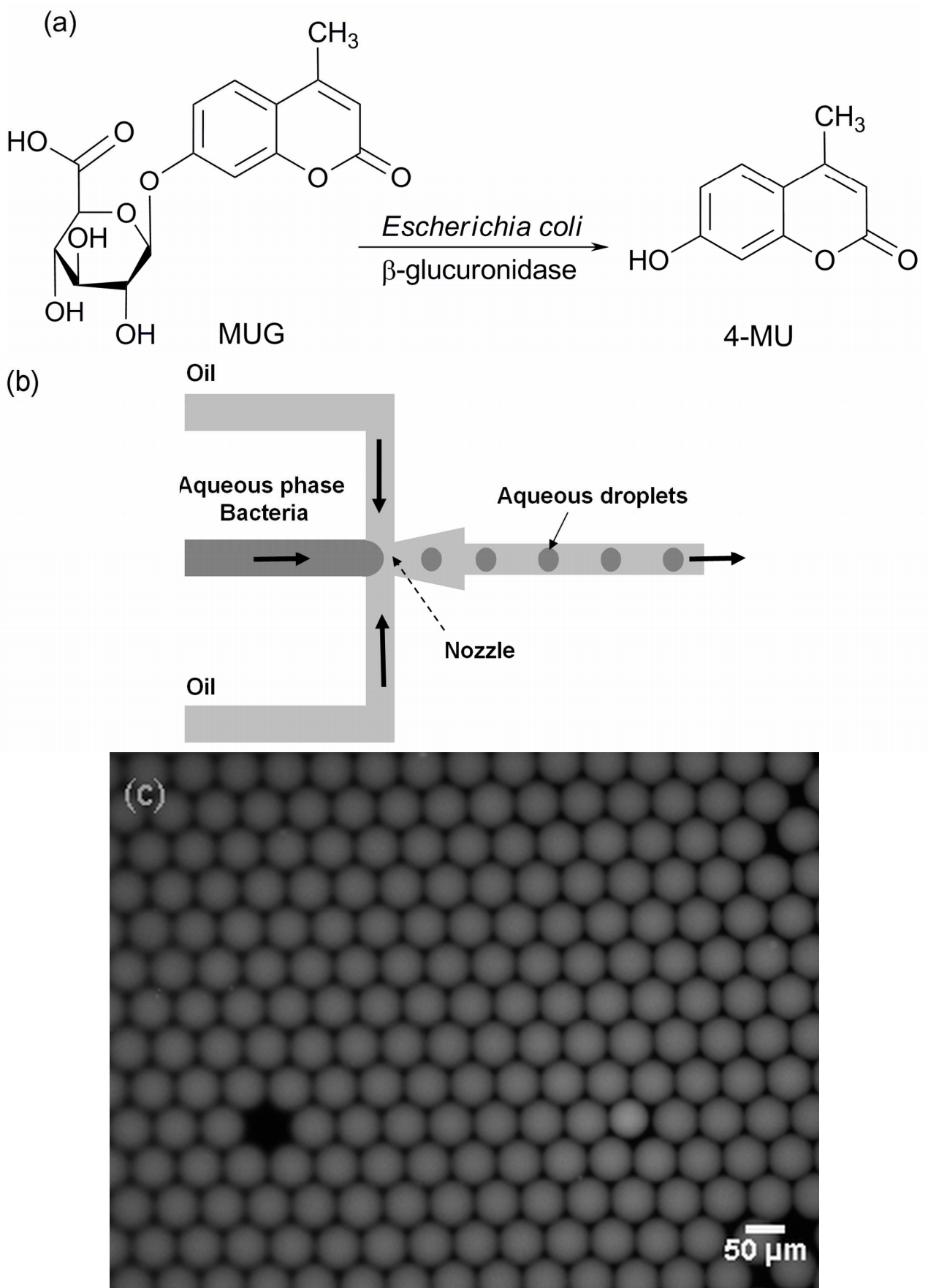

Figure 1 

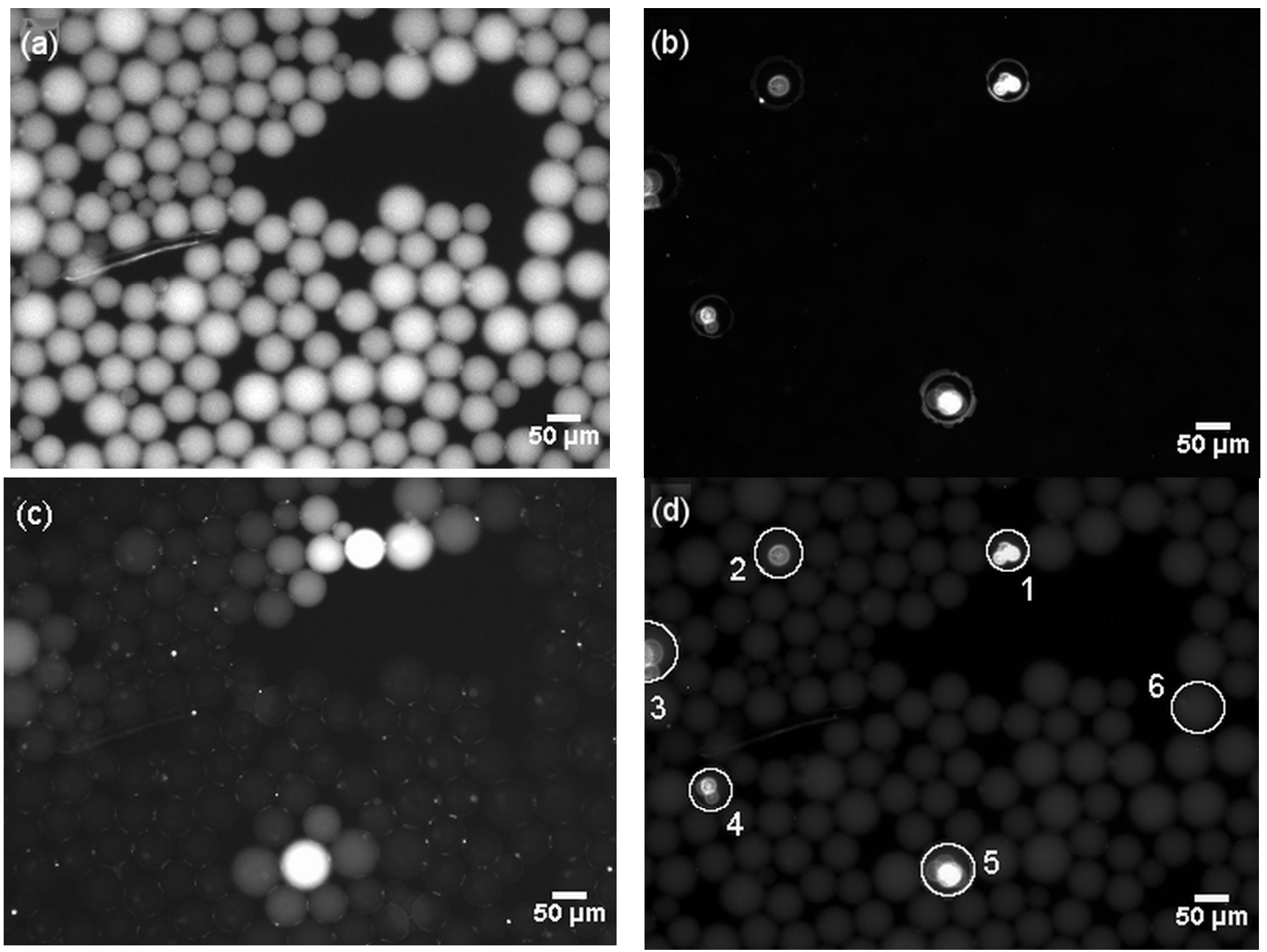

Figure 2 


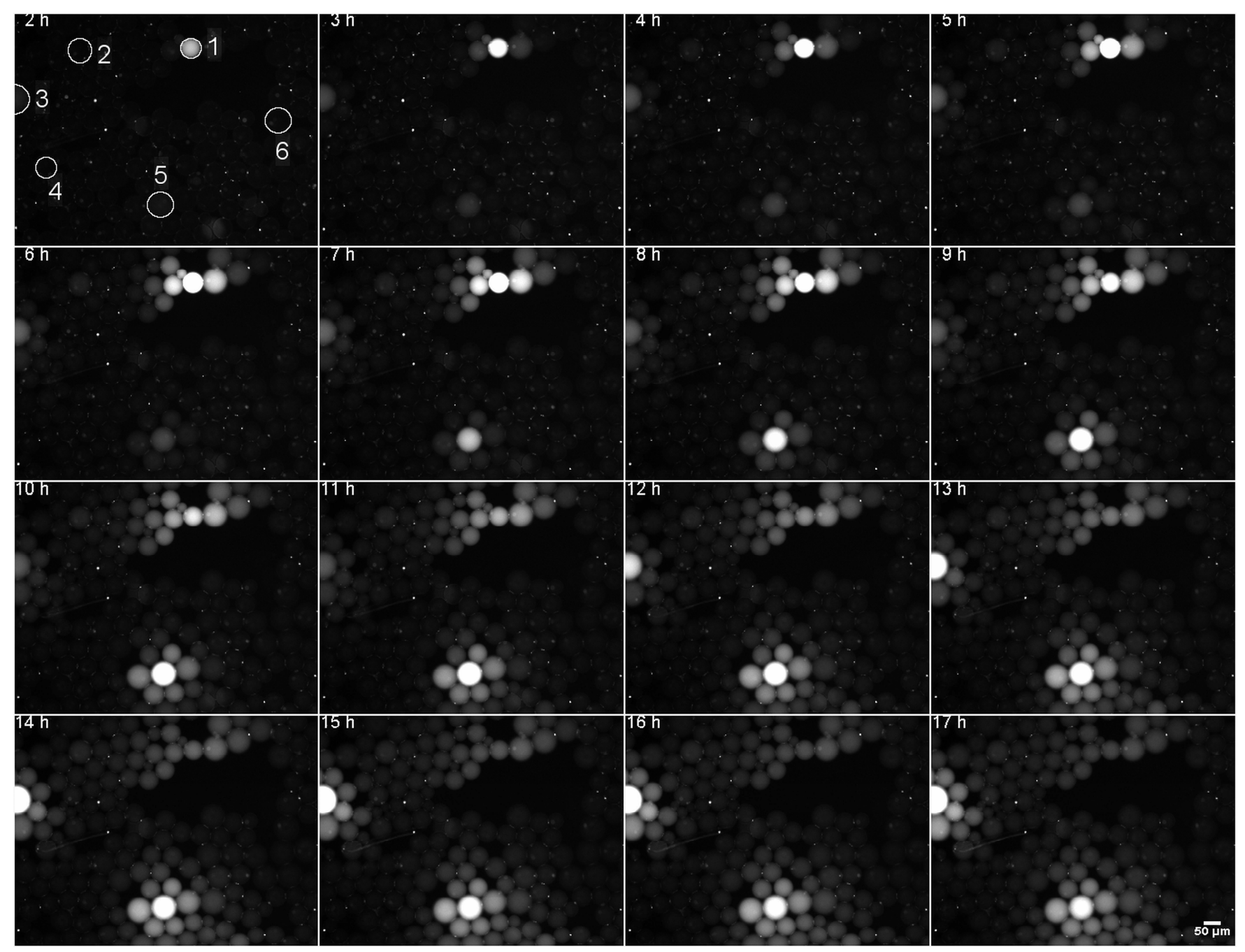

Figure 3 

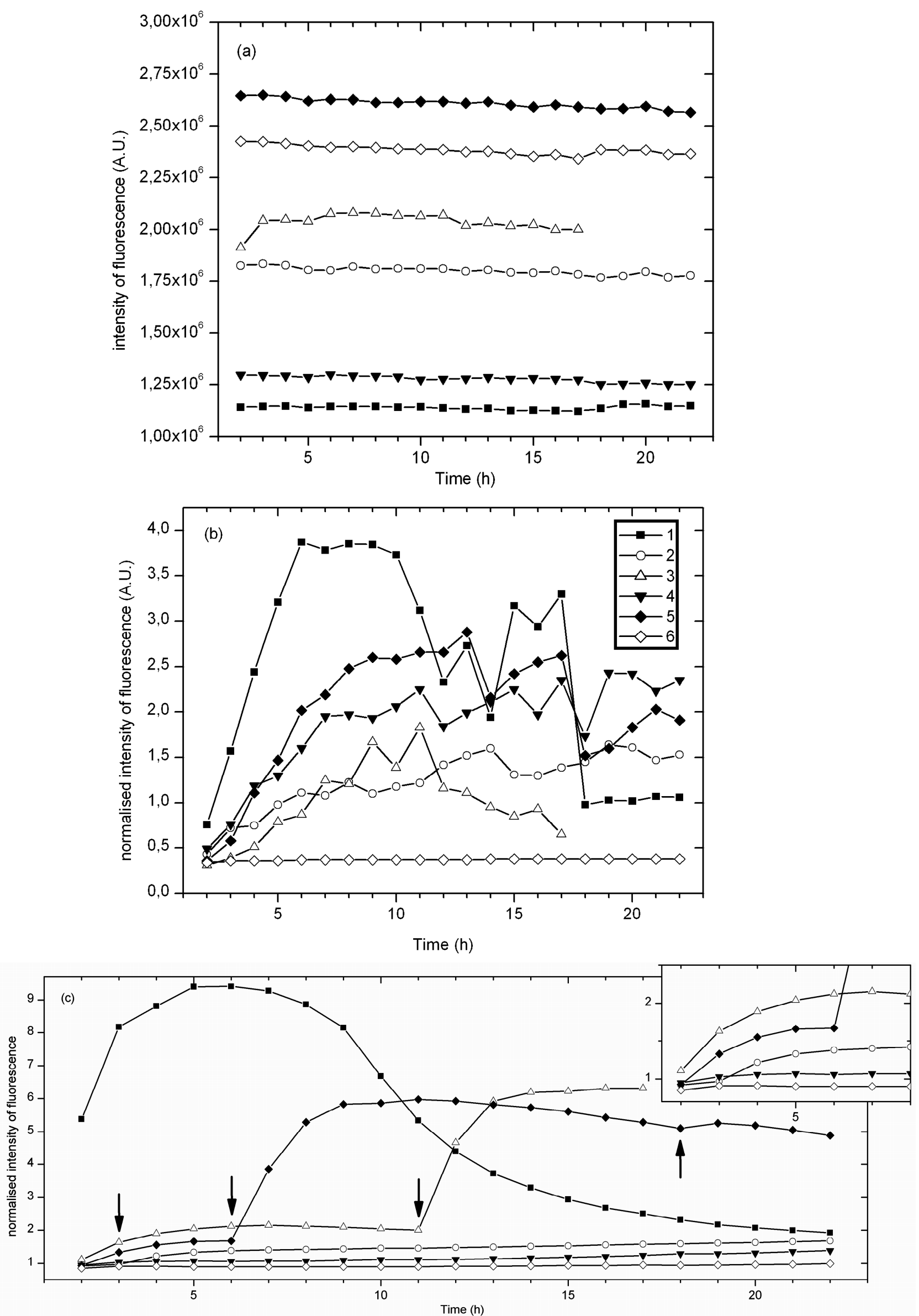

Figure 4 

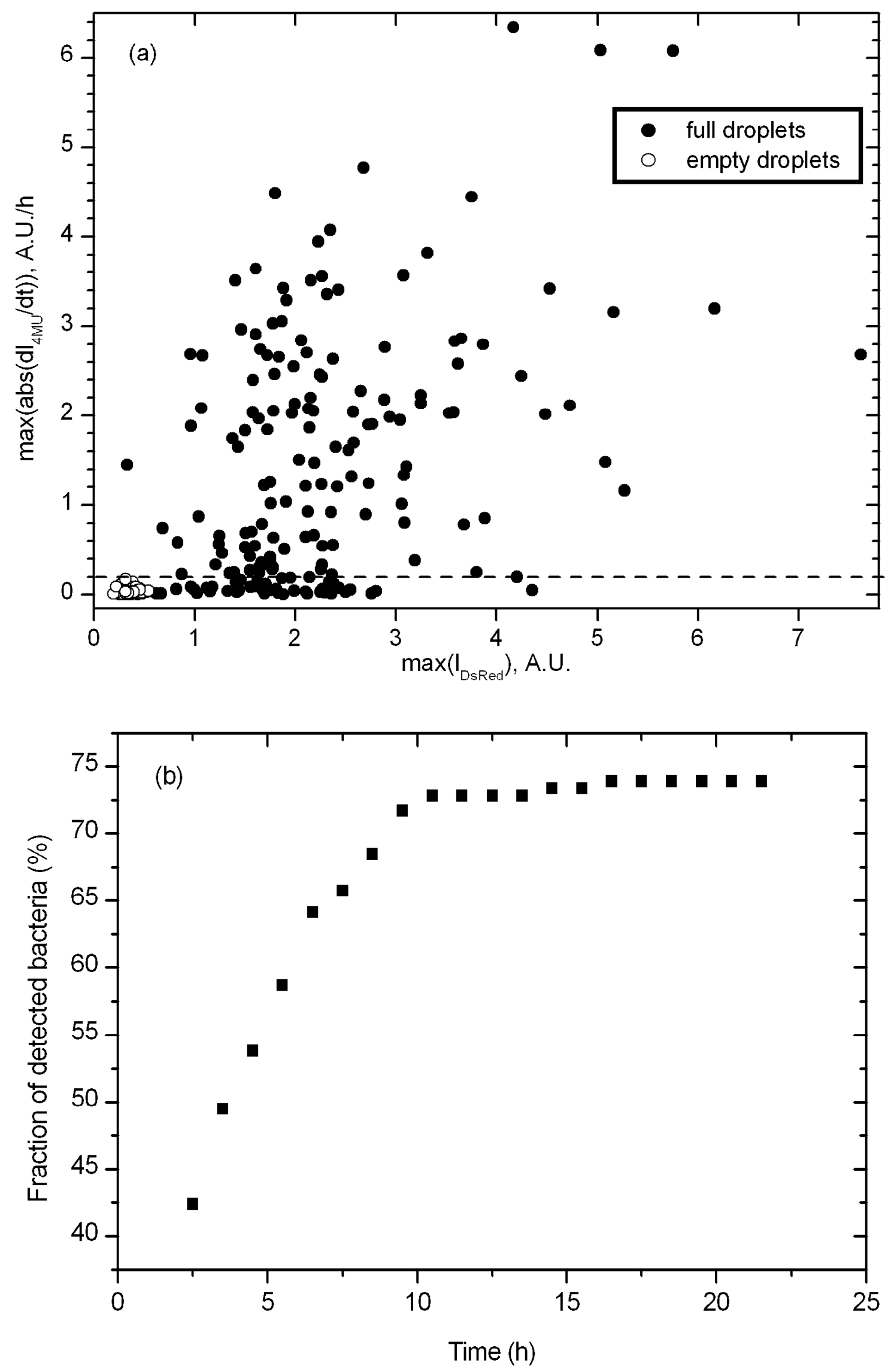

Figure 5 


\section{References}

[1] A. Huebner, S. Sharma, M. Srisa-Art, F. Hollfelder, J.B. Edel, A.J. de Mello, Microdroplets: A sea of applications?, Lab Chip 8 (2008) 1244.

[2] A.D. Griffiths, D.S. Tawfik, Miniaturising the laboratory in emulsion droplets, Trends Biotechnol. 24 (2006) 395.

[3] J.H. Leamon, D.R. Link, M. Egholm, J.M. Rothberg, Overview: methods and applications for droplet compartmentalization of biology, Nat. Methods 3 (2006) 541.

[4] R.K. Thomas, E. Nickerson, J.F. Simons, P.A. Jänne, T. Tengs, Y. Yuza, L.A. Garraway, T. LaFramboise, J.C. Lee, K. Shah, K. O’Neill, H. Sasaki, N. Lindeman, K.-K. Wong, A.M. Borras, E.J. Gutmann, K.H. Dragnev, R. DeBiasi, T.-H. Chen, K.A. Glatt, H. Greulich, B. Desany, C.K. Lubeski, W. Brockman, P. Alvarez, S.K. Hutchison, J.H. Leamon, M.T. Ronan, G.S. Turenchalk, M. Egholm, W.R. Sellers, J.M. Rothberg, M. Meyerson, Sensitive mutation detection in heterogeneous cancer specimens by massively parallel picoliter reactor sequencing, Nat. Med. 12 (2006) 852.

[5] A. Griffiths, D. Weitz, D. Link, K. Ahn, J. Bibette, Compartmentalised screening by microfluidic control, US Pat. (2005) 0221339.

[6] J.Q. Boedicker, R.F. Ismagilov, C. Kastrup, C. Gerdts, T. Huynh, H.J. Kim, M.K. Runyon, F. Shen, Stochastic confinement to detect, manipulate, and utilize molecules and organisms, Int. Pat. (2009) 048673.

[7] A. Huebner, M. Srisa-Art, D. Holt, C. Abell, F. Hollfelder, A.J. de Mello, J.B. Edel, Quantitative detection of protein expression in single cells using droplet microfluidics, Chem. Commun. (2007) 1218.

[8] C.H.J. Schmitz, A.C. Rowat, S. Köster, D.A. Weitz, Dropspots: a picoliter array in a microfluidic device, Lab Chip 9 (2009) 44.

[9] S. Köster, F.E. Angilè, H. Duan, J.J. Agresti, A. Wintner, C. Schmitz, A.C. Rowat, C.A. Merten, D. Pisignano, A.D. Griffiths, D.A. Weitz, Drop-based microfluidic devices for encapsulation of single cells, Lab Chip 8 (2008) 1110.

[10] J.Q. Boedicker, M.E. Vincent, R.F. Ismagilov, Microfluidic Confinement of Single Cells of Bacteria in Small Volumes Initiates High-Density Behavior of Quorum Sensing and Growth and Reveals Its Variability, Angew. Chem. Int. Ed. 48 (2009) 5908.

[11] J.-u. Shim, L.F. Olguin, G. Whyte, D. Scott, A. Babtie, C. Abell, W.T.S. Huck, F. Hollfelder, Simultaneous Determination of Gene Expression and Enzymatic Activity in Individual Bacterial Cells in Microdroplet Compartments, J. Am. Chem. Soc. 131 (2009) 15251.

[12] J.Q. Boedicker, L. Li, T.R. Kline, R.F. Ismagilov, Detecting bacteria and determining their susceptibility to antibiotics by stochastic confinement in nanoliter droplets using plug-based microfluidics, Lab Chip 8 (2008) 1265.

[13] S. Orenga, A.L. James, M. Manafi, J.D. Perry, D.H. Pincus, Enzymatic substrates in microbiology, J. Microbiol. Methods 79 (2009) 139.

[14] J. Cooper Mc Donald, D.C. Duffy, J.R. Anderson, D.T. Chiu, H. Wu, O.J.A. Schueller, G.M. Whitesides, Fabrication of microfluidic systems in poly(dimethylsiloxane), Electrophoresis 21 (2000) 27.

[15] I. Tryland, L. Fiksdal, Enzyme Characteristics of $\beta$-D-Galactosidase- and $\beta$-D-Glucuronidase-Positive Bacteria and Their Interference in Rapid Methods for Detection of Waterborne Coliforms and Escherichia coli, Appl. Environ. Microbiol. 64 (1998) 1018.

[16] S.L. Anna, N. Bontoux, H.A. Stone, Formation of dispersions using 'flow focusing', in microchannels, Appl. Phys. Lett. 82 (2003) 364.

[17] J. Berthier, S. Le Vot, P. Tiquet, N. David, D. Lauro, P.Y. Benhamou, F. Rivera, Highly viscous fluids in pressure actuated flow focusing devices, Sens. Actuators, A 158 (2010) 140.

[18] Y.C. Tan, V. Cristini, A.P. Lee, Monodispersed microfluidic droplet generation by shear focusing microfluidic device, Sens. Actuators, B 114 (2006) 350.

[19] L. Frenz, K. Blank, E. Brouzes, A.D. Griffiths, Reliable microfluidic on-chip incubation of droplets in delay-lines, Lab Chip 9 (2009) 1344.

[20] A. Darszon, E. Escamilla, A. Gómez-Puyou, M.T.d. Gómez-Puyou, Transfer of spores, bacteria and yeast into toluene containing phospholipids and low amounts of water: preservation of the bacterial respiratory chain, Biochem. Biophys. Res. Commun. 151 (1988) 1074.

[21] L.C. Clark, F. Gollan, Survival of mammals breathing organic liquids equilibrated with oxygen at atmospheric pressure, Science 152 (1966) 1755.

[22] C.L. Leach, J.S. Greenspan, S.D. Rubenstein, T.H. Shaffer, M.R. Wolfson, J.C. Jackson, R. DeLemos, B.P. Fuhrman, Partial liquid ventilation with perflubron in premature infants with severe respiratory distress syndrome, N. Engl. J. Med. 335 (1996) 761.

[23] J.G. Riess, Blood substitutes and other potential biomedical applications of fluorinated colloids, J. Fluorine Chem. 114 (2002) 119. 
[24] J.G. Riess, Fluorous micro- and nanophases with a biomedical perspective, Tetrahedron 58 (2002) 4113.

[25] K.C. Lowe, Perfluorochemical respiratory gas carriers: benefits to cell culture systems, J. Fluorine Chem. 118 (2002) 19.

[26] D.A. Ellis, J.W. Martin, A.O.D. Silva, S.A. Mabury, M.D. Hurley, M.P.S. Andersen, T.J. Wallington, Degradation of Fluorotelomer Alcohols: A Likely Atmospheric Source of Perfluorinated Carboxylic Acids, Environ. Sci. Technol. 38 (2004) 3316.

[27] F. Courtois, L.F. Olguin, G. Whyte, A.B. Theberge, W.T.S. Huck, F. Hollfelder, C. Abell, Controlling the Retention of Small Molecules in Emulsion Microdroplets for Use in Cell-Based Assays, Anal. Chem. 81 (2009) 3008.

[28] L. Edens, D. Meijer, P.A. Van Paridon, Stable water-in-oil emulsions, US Pat. (2000) 6013255.

[29] M.C. Pereira, U. Spiegel, Water-in-oil transparent emulsion for the skin, US Pat. (1993) 5216033.

[30] P.M. Zelisko, M.A. Brook, Stabilization of $\alpha$-Chymotrypsin and Lysozyme Entrapped in Water-inSilicone Oil Emulsions, Langmuir 18 (2002) 8982.

[31] C. Holtze, A.C. Rowat, J.J. Agresti, J.B. Hutchison, F.E. Angilè, C.H.J. Schmitz, S. Köster, H. Duan, K.J. Humphry, R.A. Scanga, J.S. Johnson, D. Pisignano, D.A. Weitz, Biocompatible surfactants for water-influorocarbon emulsions, Lab Chip 8 (2008) 1632.

[32] L.S. Roach, H. Song, R.F. Ismagilov, Controlling Nonspecific Protein Adsorption in a Plug-Based Microfluidic System by Controlling Interfacial Chemistry Using Fluorous-Phase Surfactants, Anal. Chem. 77 (2005) 785.

[33] G. Zeng, H. Fu, H. Zhong, X. Yuan, M. Fu, W. Wang, G. Huang, Co-degradation with glucose of four surfactants, CTAB, Triton X-100, SDS and Rhamnolipid, in liquid culture media and compost matrix, Biodegradation 18 (2007) 303.

[34] N.W. Fadnavis, A. Deshpande, S. Chauhan, U.T. Bhalerao, Peptide synthesis mediated by immobilized and viable baker's yeast in reverse micelles: synthesis of leucine enkephalin analogues, J. Chem. Soc., Chem. Commun. 21 (1990) 1548.

[35] L. Mariani, D. De Pascale, O. Faraponova, A. Tornambe, A. Sarni, S. Giuliani, G. Ruggiero, F. Onorati, E. Magaletti, The use of a test battery in marine ecotoxicology: The acute toxicity of sodium dodecyl sulfate., Environ. Toxicol. 24 (2006) 373.

[36] I. Effendy, H. Maibach, Surfactants and experimental irritant contact dermatitis, Contact Dermatitis 33 (1995) 217.

[37] J. Clausell-Tormos, D. Lieber, J.-C. Baret, A. El-Harrak, O.J. Miller, L. Frenz, J. Blouwolff, K.J. Humphry, S. Köster, H. Duan, C. Holtze, D.A. Weitz, A.D. Griffiths, C.A. Merten, Droplet-Based Microfluidic Platforms for the Encapsulation and Screening of Mammalian Cells and Multicellular Organisms, Chem. Biol. 15 (2008) 427.

[38] C. Holtze, R.E. Guerra, J. Agresti, D.A. Weitz, Fluorocarbon emulsion stabilizing surfactants, Int. Pat. (2008) 021123.

[39] D.A. Weitz, A. Griffiths, S. Köster, V.K. Mootha, H. Duan, J. Agresti, C.A. Merten, J. Heyman, J.R. Gilbert, Droplet-based selection, US Pat. (2009) 0068170.

[40] A. Kabalnov, J. Weers, Kinetics of Mass Transfer in Micellar Systems: Surfactant Adsorption, Solubilization Kinetics, and Ripening, Langmuir 12 (1996) 3442.

[41] A. Kabalnov, Ostwald ripening and related phenomena, J. Dispersion Sci. Technol. 22 (2001) 1.

[42] B.P. Binks, J.H. Clint, P.D.I. Fletcher, S. Rippon, S.D. Lubetkin, P.J. Mulqueen, Kinetics of Swelling of Oil-in-Water Emulsions Stabilized by Different Surfactants, Langmuir 15 (1999) 4495.

[43] M.Y. Koroleva, E.V. Yurtov, Water mass transfer in W/O emulsions, J. Colloid Interface Sci. 297 (2006) 778 .

[44] J. Jiao, D.J. Burgess, Ostwald ripening of water-in-hydrocarbon emulsions, J. Colloid Interface Sci. 264 (2003) 509.

[45] B. Valeur, Molecular Fluorescence. Principles and Applications, ed. Wiley-VCH, Weinheim, 2002.

[46] A. Huebner, D. Bratton, G. Whyte, M. Yang, A.J. deMello, C. Abell, F. Hollfelder, Static microdroplet arrays: a microfluidic device for droplet trapping, incubation and release for enzymatic and cell-based assays, Lab Chip 9 (2009) 692.

[47] M.V. Matz, A.F. Fradkov, Y.A. Labas, A.P. Savitsky, A.G. Zaraisky, M.L. Markelov, S.A. Lukyanov, Fluorescent proteins from nonbioluminescent Anthozoa species, Nat. Biotechnol. 17 (1999) 969.

[48] H.M. Shapiro, Practical Flow Cytometry, fourth ed., John Wiley \& Sons, Inc., Hoboken (NJ), 2003. 